\title{
Un principio definitivo para una crítica contemporánea
}

\author{
A definitive principle for contemporary critique
}

\author{
Wilfrido H. CorraL * \\ Academia Ecuatoriana de la Lengua \\ sancorhw@gmail.com
}

https://doi.org/10.32719/13900102.2018.43.5

Fecha de recepción: 12 marzo 2018

Fecha de aceptación: 30 mayo 2018

\section{RESUMEN}

El autor se centra en Epílogo provisional de Elena Santos; señala algunos desencuentros y destiempos para la interpretación de la narrativa hispanoamericana contemporánea producida por la crítica española. El libro de Santos es una gran excepción al no considerar avatares académicos, y como tal es un principio ejemplar para ella y la crítica latinoamericanista en general.

PALABRAS CLAVES: novela hispanoamericana, Elena Santos, estado de la crítica contemporánea Hispano-americana.

\section{ABSTRACT}

Focusing on Elena Santos Epílogo provisional, this article points out some disengagements and mistimings in the interpretation of contemporary Spanish American narrative by Spanish criticism. Because of its precluding academic avatars Santos' book is a great exception, and as such an exemplary beginning for her and Latin American criticism in general.

KEYWORDS: Spanish American novel, Elena Santos, state of contemporary SpanishAmerican criticism.

\footnotetext{
Ecuatoriano. Se doctoró en Columbia University. Su Condición crítica y El error del acierto analizan el estado de la crítica. Autor de libros sobre Monterroso, Bolaño y Vargas Llosa, sobre la novela ha escrito Cartografía occidental de la novela; y co-editado Los novelistas como críticos, I y II, y The Contemporary Spanish-American Novel: Bolaño and After. Con Daphne Patai es autor del seminal Theory's Empire. Su libro más reciente es Discípulos y maestros 2.0. Novela hispanoamericana hoy (2019).
} 
Desde siempre, y en la actualidad más que nunca, se cuestiona qué hay de nuevo en la crítica literaria, cómo concebir otra sin comenzar de nuevo (o solo con base en lo novedoso); y en el caso de una crítica con lengua y culturas móviles, quién la presenta sin una ideología de apropiación cultural, sin ver todo como propiedad intelectual o nacional, sin privatizar el capital cultural que pertenece a muchos. Hoy cuando casi todo el mundo tiene o cree tener derecho a un "relato" (vocablo más exacto que "narrativa"), y cuando todo cuesta algo, los críticos no se quedan atrás con los suyos, aunque sus relatos contengan la semántica negativa asociada con escribir "historias" o "cuentos".

Quizá por esos contextos más y más tautológicos la española Elena Santos es modesta y cautelosa al llamar a su libro Epilogo provisional. Una cierta tendencia de la narrativa latinoamericana actual (2017), porque cada vocablo del título implica mucho más que su significado, idea que quiero transmitir con mi propio título. Diferente de otros críticos españoles e hispanoamericanos cuyas contribuciones para compilaciones he examinado en otros momentos, sus artículos, notas críticas y reseñas en torno a la narrativa hispanoamericana contemporánea están entre las interpretaciones más sagaces sobre autores y obras muy volubles (Corral 2015, 355-81).

La plusvalía erudita de Santos tiene muy poco o nada que ver con el discurso universitario de excesos, con frecuencia dañino para la interpretación según ella (Santos, 19), especialmente si se considera el peaje profesional, derecho ético o tributo institucional que más de un crítico reciente cree que debe o tiene que pagar. El propósito principal de dedicarse a un libro crítico es aprender de ideas estimulantes, a pesar de que los libros cosidos de una serie de textos sueltos nunca han sido una buena apuesta para experiencias lectoras centelleantes. El tipo de crítica empleado por ella -atípico entre el latinoamericanismo literario actual en español- será novedoso y desafiante para el público especializado al que seguramente llegará; y en última instancia es dentro de esa circunstancia que se puede medir su recepción y vigencia, eventualidades que podrían incumbir más a académicos susceptibles, club al que no pertenezco. Los trabajos que ha escogido Santos fueron divulgados en España, por lo general fuera de los circuitos institucionales oficiales, lo cual les otorga una libertad encomiable, si bien la mayoría fue publicada por la revista Guaraguao, afiliada a la editorial que publica su libro.

Acaso para evitar desvíos en la acogida de ellos como conjunto su título es tentativo, en contrapunteo con sus acertadas opiniones. En realidad este es un libro más meditado que otros recientes como Viceversa. 
La literatura latinoamericana como espejo (Barcelona: Paso de Barca, 2018) de Constantino Bértolo y Paisajes en movimiento. Literatura y cambio cultural entre dos siglos (Buenos Aires: Eterna Cadencia, 2018) de Gustavo Guerrero.

A la vez es un segundo (el precursor es Desvíos: un recorrido crítico por la reciente narrativa latinoamericana de Ignacio Echevarría en 2007) intento cabal por cartografiar desde España una narrativa sin mapamundi, en una nueva editorial pequeña, que como sus pares hispanoamericanas puede sufrir de la condena de la edición nacional, no obstante su calidad. Además, Epílogo provisional ha sido armado sin tratar de sosegar la abstinencia de aquellos críticos aliados desesperados por ver sus nombres citados. Santos, que no cita críticas publicadas en la revista que publicó la mayoría de sus textos, tampoco privilegia agendas estéticas, o ideológicas ligeras martilladas como si fueran lo único que se puede decir en esta época de "posverdad digital". Tampoco pretende autorizarse o legitimarse con referencias del último grito exegético o llamados a presuntas autoridades ensimismadas en su coto institucional, gesto que funciona a su favor.

En el Prólogo a su Ficciones argentinas (2012) Beatriz Sarlo, crítica canónica a veces institucional, llama “ensayos" a las reseñas que recoge, percepción que vale comparar con la parsimonia de Santos al juntar las suyas de los últimos quince años, añadiendo una "Introducción" y una última parte ("Generalidades") más extensas como sujetalibros. En su prólogo Sarlo se dedica más a lo que manifiesta que es o debe ser escribir crítica [hoy], rito obligatorio en varias compilaciones o estudios sueltos contemporáneos que se puede examinar como representativas de hacia dónde se mueve la crítica latinoamericanista. Aun creyendo que nunca habrá objetividad total en la crítica, siempre existirá la honestidad intelectual que permite superar nuestros credos críticos y recalibrar nuestras afirmaciones con base en nuevos datos y a partir de hechos que antes no conocíamos. Santos sabe qué lo que quiere hacer y prosigue sin miramientos, razón por la cual su libro debe suscitar más que reseñas.

Por eso, si discrepo de otras, comparto prima facie dos propuestas de Sarlo: "No tenía como objetivo demostrar ninguna hipótesis general, ni decir para qué lado va la literatura (una forma casi segura del error). Si algunas ideas permanecen, mejor. Pero no fue una de mis obsesiones"; y "Es sabido que la crítica literaria le importa a muy pocos. La prosa académica le ha hecho perder vibración", que supone que la crítica solo se mueve en la academia. Por ignorar esas condiciones algunos críticos piden "hipótesis" sin colegir que esta es por definición exclusivista, o que un papel propio del crítico debería ser cuestionar dogmas aceptados ("tesis"), 
incluso alguno suyo; concebir nuevos métodos de análisis y expandir los términos del debate público sobre deficiencias ("antítesis"), sin pretender llegar a una "teoría" ("síntesis") en que solo ellos creen. El proceder de Santos en las cuatro secciones principales de su libro acata estas precisiones.

Ella tiene razón entonces al parcelar las tendencias y desarrollos que estudia en cuatro secciones dedicadas respectivamente a la autoficción (término que algunos críticos tienden a confundir con variantes de la “autobiograficción”), Historia, distopía y metanovela (la más extensa). Cada una de las veintiséis novelas que selecciona se ajusta bien a los apartados en que las ubica. Pero precisamente por ser novelas dejan espacio, por ejemplo, para que se piense en la preponderancia de lo rural (vastamente reimaginado hoy) en varias narradoras argentinas (Selva Almada, Ariana Harwicz) de la generación más reciente, no necesariamente la de "los padres".

Concebir varias obras actuales como hace ella no quiere decir que todas tengan similar calidad o sean representativas; y si hay algunas que no se reconocerá se las puede pensar como aquellas a las que se les podría acreditar el beneficio de la duda o que se debería redimir, gesto común en muchos críticos de la narrativa contemporánea. Las que examina Santos son comparables, parecidas, y serían lo único que queda si lo único que hicieran es reciclar intentos fallidos de superar las características genéricas registradas por ella (193). En ese sentido no hay ningún problema con que incluya al español Isaac Rosa en el apartado dedicado a la Historia, aunque su conexión hispanoamericana es extremadamente tenue en comparación con la influencia revisionista que han tenido Juan Goytisolo y Javier Marías, y más en este siglo Enrique Vila-Matas y Javier Cercas entre sus discípulos y algunos maestros iberoamericanos.

La Introducción de Santos asevera que el principal rasgo que hermana a sus autores es "una autoconciencia narrativa que obliga a cualquier hermeneuta a actuar a partir de una lectura muy lejana a la disertación historiográfica" (15), e inmediatamente manifiesta que un concepto que atraviesa su libro "de principio a fin" es el agotamiento de la posmodernidad. Su resumen (19-23) del contenido de las secciones de su estudio advierte que "carece de títulos imprescindibles que inevitablemente han quedado fuera por motivos y criterios no precisamente cualitativos" (23), y resalta su modestia articulando que la suya "continúa siendo una semilla que todavía no sé muy bien en qué desembocará” (24).

Se acepta su llamado, por lo que deja fuera. Por esa razón, aun estando de acuerdo con que no se requiere un "aparato crítico" para interpretar con autoridad, será evidente para el tipo de lectores al que va dirigido Epilogo 
provisional que, si no están varios autores que ellos quisieran, entre otros brillan por su ausencia César Aira, Horacio Castellanos Moya, Rodrigo Rey Rosa y Alejandro Zambra; más los mexicanos Cristina Rivera Garza, y Julián Herbert. Para otra edición, más allá de aceptar la subjetividad de nuestro quehacer y del "Temo al hombre [sic] de un solo libro" de Tomás de Aquino, faltarían algunas diseñadoras del futuro de nuestra narrativa: Valeria Luiselli, Harwicz y Mónica Ojeda (en ese orden) y por encima de todas ellas hasta hoy, Rita Indiana.

Epilogo provisional demuestra que entender la narrativa contemporánea no requiere un viaje a una semilla sino a varias de ellas, porque al ocuparse de imperativos distintos se puede postergar obras actuales y algunas pasadas que no se conoce en la esfera generalmente exitosa en que se han instalado algunos de los autores que discute. Si para Santos la ironía (190-194), y según su Introducción, es la característica que más comparten los que examina, también vale diferenciarlos sin disimulos o consideraciones personales. Salirse de la "linealidad narrativa" no explica varias propuestas más complejas de muchos autores actuales, y la crítica no se decide respecto a orígenes reales, mundiales o locales y las posibles relaciones entre ellos. Como escritores los novísimos entienden las necesidades y desigualdades del talento. Sus características, resumidas, no son su dominio o práctica exclusiva, ni tampoco lo fueron para sus antecesores inmediatos o, de hecho, para la historia de la narrativa con que conviven (191). De más está decir que esas características componen el tipo de ensamblado dinámico algo repetitivo que caracteriza al movimiento de la conciencia contemporánea y sus dilatados antecedentes.

Santos explora con convicción algunas querellas vigentes sobre la dependencia socio-económica de los años setenta, el neoliberalismo como bestia negra o comodín, el propagado tema de la violencia, la creciente presencia de las artes plásticas, la injerencia de los nuevos medios en la narrativa, y algunos esencialismos temáticos que imposibilitan hablar de "una ruptura absoluta" (195). Ante esos cruces trillados que posibilitan la movilidad o desplazamiento genérico en el caso de novelistas como Damiela Eltit y otros que emplean los excesos teóricos como protagonistas, ya en 1999 el crítico Donald Shaw señalaba que corren "el riesgo de la ilegibilidad". Igualmente, si en su revisionismo algunos críticos comprometidos no se dedican a obras autoconscientes puede ser porque hoy aquellas pertenecen a una categoría cada vez más insignificante, que implica que los géneros siguen estancados o, peor, que los intentos de renovación recientes son más complejos que los anteriores.

Aquellos son debates más que complejidades o realidades empíricas 
definitorias porque cierta crítica académica transoceánica los problematiza con las buenas intenciones y el tono celebratorio y triunfalista de un panhispanismo comercializado que otro crítico español, Bértolo, ha llamado "Españacentrismo". Se puede suponer sin riesgo que en sus cavilaciones Santos se refiere, casi sin nombrarlas, a las vetas académicas y periodísticas del latinoamericanismo español, y en ese sentido vale tener en cuenta que varios de los autores de la cohorte de la cual se ocupa han vivido o viven y trabajan en España, donde algunos de ellos se han doctorado en letras.

Si Santos y los autores cuyas obras analiza son casi uniformemente discretos respecto a esas condiciones y ocupaciones, sin puntadas sutiles el mexicano Juan Pablo Villalobos, que ha seguido cursos de posgrado en España (con una tesis sobre Pablo Palacio) y sigue viviendo allí, destapó hace un par de años una caja de Pandora al aseverar (y generalizar) en una entrevista española (Quimera, noviembre de 2017): "Se aprende más en las universidades latinoamericanas que en las españolas. Mi experiencia con la academia española fue francamente mediocre". No se puede deducir por qué hay que ver así las cosas, porque las literaturas son compartidas, como muestra el amplio registro de autores ausentes que subjetivamente Santos podría considerar menores. Sin embargo Villalobos tiene mayor razón al decir: "El discurso de la posmodernidad se había cargado mucho del rigor teórico y con frecuencia en las aulas se decían puras chorradas, las discusiones del doctorado muchas veces no se diferenciaban de charlas de café", criterio que se puede matizar refiriéndose al discurso de la contemporaneidad que hace caso omiso de la posmodernidad.

Esos desencuentros -porque distanciarse de fuentes como la trillada posmodernidad no es un gesto sin virtud en sí- son solo uno de los factores que permiten resemantizar varios "clásicos" contemporáneos, uno de ellos, Bolaño, analizado por Santos. La crítica especializada que enfatiza esos desvíos (a la vez exacerbando los destiempos concomitantes) casi nunca se centra en los textos, y por ende las lecturas revisionistas de Santos proveen una corrección ineludible al no desplazarse hacia puntualizaciones convenientes para una casa de citas o la subjetividad y excesos que se puede construir de ellas. Contrario a ese proceder sus análisis de Rafael Gumucio y Wendy Guerra bajo la rúbrica "autoficción" se dirigen implícitamente a la llamada "literatura de los hijos", y no es menor la implicación para la historia literaria cuando bajo esa categoría analiza una crónica de Juan Villoro y los problemáticos (como narración fiable) diarios iniciales de Ricardo Piglia, especialmente porque no hay obras monumentales que sean más que monumentos a sí mismos. Aun así, se aprende mucho más 
de la hibridez de Héctor Abad Faciolince y la constancia proba de su prosa. Por similares ausencias hay algunos desencuentros entre su recatada Introducción y las sustanciales "Generalidades" (título que también muestra la templanza de una crítica que no tiene nada de principiante) que conforman la quinta sección de Epilogo provisional.

La Introducción también ofrece más espacio para divergencias, especialmente cuando postula con frecuencia que de varias maneras la narrativa contemporánea es un tipo de corrección del posmodernismo. Es claro que la mayoría de la narrativa de nuestro continente se deslindó de esa cosmovisión cultural, vigente solo para algunos críticos ininteligibles empedernidos; pero es más arduo rastrear huellas conceptuales de la denigrada actitud posmoderna para contar una historia, aun reconociendo algún valor suyo. Al manifestar querer "desafiar al escepticismo teórico mediante el poder de sugestión de una ficción que ya ha alcanzado otro estadio" (17, énfasis mío), y apostillar que ofrece "un panorama todavía en plena mutación", Santos describe problemas primordiales de la interpretación actual. Ante el relativismo interpretativo reinante no es el trabajo de los críticos proveer un "espacio seguro", tan de moda en el mundo anglófono, porque de pagar ese peaje estarían traicionando su propósito secular, socavando sus propias interpretaciones y zona de seguridad. Por eso, que ella sostenga enseguida que los relatos escogidos se cimientan en "una poderosa voluntad de estilo" no fortalece totalmente el propósito de su propia interpretación, porque más o menos lo mismo se decía del boom o de autores y obras olvidadas o excluidas que no hicieron boom, u otras de lo que va del siglo.

Las seis partes de la sección "Generalidades" con que termina Epilogo provisional notan claves irónicas en casi cada obra, y las contextualizan más entre sí que con obras del pasado, elección que hace pensar que esta sección del libro debía haber sido la Introducción; y ésta habría funcionado mejor como la última, en particular cuando provee una lista de los autores que están o no están (183). Si se puede generalizar que todos esos autores son cosmopolitas, a pesar de sí o de lo que crean los críticos preocupados por la periferia, Santos acota razonable y discretamente que peligran la ligereza textual y la sofisticación de la prosa. Pero es más arriesgado aseverar que "por esa búsqueda desesperada del cosmopolitismo en detrimento de lo localista, se pierda la identidad nacional y a veces resulte difícil distinguir entre un libro de un autor argentino y otro de un colombiano, por ejemplo" (192).

Hay algo de verdad en esa visión, pero el cosmopolitismo no es ni debería ser un problema para autores y críticos, porque de lo contrario se 
vuelve a un esencialismo de identidades complejas que los hipersensibles se ponen y quitan como ropa, y que sigue teniendo graves repercusiones, generalmente entre autores y obras de países o literaturas "pequeños" o "menores". Ese cosmopolitismo rige no solo porque ella afirma que han leído a Borges, el más atípico de los padres literarios, "sino también toda la literatura occidental posterior a él" (196); también existe porque a decir verdad ni los autores ni los críticos tienen que pagar un derecho de admisión a la mundialización, lo cual obliga a preguntarse por qué algunos críticos asumen posturas serviciales ante los que Antoine Compagnon ha llamado "los demonios de la teoría". Es difícil constatar si los últimos nuevos han leído toda esa literatura, o resúmenes en la red; pero no que es muchísima más que las de sus países o padres locales, giro ya patente desde Darío. Vale recordar que Vargas Llosa, influencia habitualmente admitida por muchos de los autores presentados en Epilogo provisional, lleva décadas mostrando por qué a un novelista hispanoamericano contemporáneo no se le debe ocurrir equiparar su obra con su nación de manera patriótica y sin matices, y se puede defender que los discípulos han aprendido bien su lección.

Si la cuarta sección, dedicada a la "metanovela" hace bien en sacar al proscenio obras de Margo Glantz, Juan José Becerra y Victoria de Stefano (en ese orden), a la vez que confirma y justifica la presencia de Bolaño, Alan Pauls, Patiricio Pron, Rodrigo Fresán y Andrés Neuman (también en ese orden), cuesta precisar qué papel han jugado Ruiz Sosa y particularmente Sergio Chejfec en el desarrollo de esos cuestionamientos de sí mismo y del acto de escribir una novela, sobre todo considerando la confirmada trayectoria de los ya mencionados Aira y Zambra, junto a los cuales se justifica examinar las obras del colombiano Santiago Gamboa o del ecuatoriano Leonardo Valencia, radicados en el extranjero en varios momentos.

Si es verdad que por tradición y tamaño la narrativa argentina predomina en su reproducción y presencia española, se haría bien en poner en perspectiva autores que no han tenido una buena acogida general, o en la prensa internacional, como Chejfec. En ese sentido, la "distopía" de que se ocupa la tercera sección de Epilogo provisional es excepcionalmente sólida y significativa como análisis de un tema relativamente ausente en Hispanoamérica. En ese contexto sus interpretaciones de las poco conocidas El señor amarillo del mexicano Adrián Curiel Rivera y Navidad y Matanza del chileno Carlos Labbé son muy buenas presentaciones de dos autores que, por válidos y prometedores que sean, no tienen una gran novela. 
Así, del primero dice: "Se trata de un recurso irónico para hacernos cómplices de una estrategia de 'recuperación' de los códigos de la novela experimental" (96); y del segundo: "De todo ello no debe deducirse que este sea un libro de proporciones monumentales. Se trata de una novelita compuesta por capítulos breves -algunos brevísimos-, de reducida extensión y escritura diáfana" (101). Sobre El Tercer Reich de Bolaño su evaluación no puede ser más admirativa de la habilidad e imaginación del chileno para identificar, juego, literatura y vida "en una pirueta de raíz posmoderna" (119), y no hace menos con Arrecife de Villoro. Si para esos contornos no se echa de menos completamente alguna atención al tribalismo del grueso del Crack o de buena parte de McOndo, en estos recorridos faltan autores cubanos menos mediáticos que Guerra y una tasación de la recepción de otros autores y obras, un diálogo con críticos del viejo continente y sobre todo de las dos Américas; y en el caso de esa tercera sección, una conclusión sobre el tema de la distopía.

Para esa temática Labbé es un autor más y más reconocido, y su reciente Coreografías espirituales (2017) es una distopía musical digitalizada, en que el protagonista parapléjico percibe la desescritura de su memoria y sus relatos. Pero el chileno no se puede escapar de contar historias. Respecto a la recepción del prolífico Villoro, en la primavera de 2010 la notoria revista neoyorquina de avanzada cultural, $N+1$, lo presentó como el mejor escritor mexicano no traducido -en 2015 se tradujo una selección de su cuentos; y en 2017 Arrecife, quizá su mejor novela, examinada por Santos junto a otras dos de él (119-123)- lo cual pone en perspectiva los “descubrimientos" de varias revistas anglófonas y de la crítica fuera del país natal de cada autor.

Menciono esa realidad porque Santos no considera si sus autores tienen proyección internacional, consideración relacionada a la producción de más de una obra memorable, y el hecho es que todavía no hay un Bolaño entre ellos. Santos tampoco cuestiona cuánto de una novela distópica se traduce bien al momento contemporáneo, o si debe responder a ansiedades actuales. Aquellas no son un gran favor como mensaje, porque las distopías, características de este siglo no del veinte (aunque el término fue acuñado en 1868 por John Stuart Mill), ya no son ficciones de resistencia sino de sumisión, de un siglo solitario y taciturno que no confía en nadie o nada. Ya no son un llamado al valor sino a más cobardía y desesperación, porque no se pueden imaginar un futuro mejor.

Por esos destiempos la segunda sección de Epílogo provisional, dedicada a la Historia es las más contundente y convincente como agrupación en torno a un concepto, aun teniendo en cuenta lo ya 
manifestado sobre Rosa. Santos comienza con un autor aleatorio al boom, Jorge Edwards, y termina con la excelente El ruido de las cosas al caer de Juan Gabriel Vásquez, uno de los más jóvenes de los autores examinados. Esos polos le permiten cubrir la Historia (debidamente con mayúscula) que sigue siendo la fuente necesaria y maleable para gran parte de los narradores que escriben hoy, no importa cuál sea su "generación".

En esta sección sobresale la novelística de Villoro, y si no convence que Santos despegue para su análisis de El testigo viéndola como un desbordante resumen de los modos "posmodernos o manieristas" (61) actuales, sí se puede comprobar ver en ella un "sinfín de alusiones culturalistas y populares, con referencias a lo mitológico y al corpus literario hispánico" (65). Como ella admite a través de su análisis, lo libresco se templa con lo popular en la narrativa actual. Pero lo culto y hasta clásico predomina, y la visión que da de Vásquez se asemeja a la de numerosos autores no incluidos cuando Santos mantiene que "Sus referencias van más allá de su nacionalidad, se siente vagamente heredero del boom, aunque más bien confiesa considerarse un hijo espurio de sus autores de cabecera, maestros todos ellos de las letras contemporáneas..." (88). Con razón concluye que Vásquez es un autor audaz, nada críptico (92), desenlace afín con el gatillo de su nota: que Vásquez "responde a la perfección al perfil del joven escritor latinoamericano cosmopolita" (88).

Respecto a temas como la cultura popular, la sexualidad y la situación de las mujeres en las cosmovisiones que estudia, Santos da varias vueltas sin llegar a conclusiones demasiado satisfactorias, para ella; o sea que tiende a aferrarse a su formulación, sin espigar más. ¿Pero no es ese el "ensayismo" que debe mostrar un buen comentario? Creo que sí. Si opina que sus autores coinciden en la seguridad demostrada de sus esfuerzos, lo mismo se puede decir de ella, y por eso su rescate (porque no ha tenido la recepción que merece) de Ciencias morales, del argentino Martín Kohan, cabe perfectamente en la sección sobre la Historia, porque como las otras novelas relata bien y transmite "la reflexión histórica sin explicitar en demasía el discurso político" (87), más las ambigüedades del poder y el despertar de los sentidos en los jóvenes. Si como crítica Santos provee pedagogía generacional sobre los matices y repercusiones perdurables de su quehacer personal, su práctica también es un aviso riguroso de la dinámica de género hoy, en parte por la ausencia de mujeres en su muestra, elección a la cual tiene todo derecho, así como un crítico varón descarta a otros autores, por control de calidad.

Las diferencias mayores que se quiera encontrar en los análisis de Santos no caben en los valores relativos de los autores que estudia, sino en 
cómo o si la crítica del hegemónico primer mundo otorga a los escritores hispanoamericanos el mérito que merecen. Tarde o temprano un autor o crítico "no occidental" será visto como representante o portavoz de una comunidad, nación o raza que no quiere personificar, y Santos evade esa propensión. No obstante, ella enaltece el renovado y continuo interés español, académico o periodístico, por la narrativa más reciente -avanzado con la crítica del profesor Eduardo Becerra, del crítico cultural Echevarría, y recientemente con otros matices con el de la profesora Ana Gallego Cuiñas y Santos- y sirve como termómetro estético y editorial.

Peritos, ellos suponen que se sobreentiende cabalmente la narrativa anterior, razón por la cual no se dedican a toda la narrativa del continente. Esa opción ha conducido, particularmente en el mundillo del saber académico, a brechas conceptuales en visiones panorámicas y sumarios de "fin de año" que son menos objetivos, a veces repletos de agendas o cuotas. Pero los críticos tienden a dedicarse a las obras disponibles, así que también habría que considerar cómo las editoriales independientes o pequeñas son componentes desiguales de una sub-economía de intercambio, cuyos mediadores o prescriptores son agentes, críticos estrella, entrevistadores, fundaciones, grupos de lectura, libreros, mecenas, "onegeros" culturales, traductores, la manipulativa cultura de la disrupción de las redes sociales, y en un estadio menor el impulso profesoral de corregir.

Como si eso fuera poco, en esa economía de influencia pugnan el talento real, los falsos expertos, las ferias del libro, las polémicas y los premios; en fin, una literariedad confabulada. El diálogo de sordos contemporáneo sobre los libros y las ideas, es obvio, excede los contextos tradicionales. Los seminarios académicos, las reseñas de los usuarios de Amazon, sitios como Goodreads, la radio, la redifusión multimedia (podcasts) y a veces la televisión hacen que la calidad, la forma y el tono de la cobertura tengan una vasta movilidad y variedad. La conversación sigue, porque no se sabe si todo ese andamiaje, como el de la crítica, beneficia al negocio del libro. En ese contexto ocurre con frecuencia que una mala idea indica el lugar de una buena idea, a la vez que establece una constelación de otras ideas. Además, hay que considerar que la cantidad de contenido original que se escribe, mira o discute debido a los nuevos medios no tiene precedente. Al escribir se está en una posición fuerte, pero a la vez difícil, sobre todo si el crítico se percibe a sí mismo como salvador, pero sin el poder redentor de los ya establecidos que tiene a su alrededor.

Con las excepciones que acabo de mencionar, entre aquellos prescriptores abunda el apego a lo exótico como modus vivendi 
latinoamericano representativo, y algunos nuevos narradores y críticos con poca obra y misión redentora ceden a fórmulas impuestas desde un "afuera" teorizado excesivamente, que dicen ser su "adentro"; y por no ver la contradicción convierten en borroso lo que podría ser novedoso o diferente en sus historias. Para Santos los nuevos narradores "en su huida de lo exótico y lo pintoresco, la inclusión de dialectalismos no deja de ser un guiño autoconsciente, pero no trabajan las figuras retóricas o los juegos de palabras de una manera tan exacerbada" (191). Pocos críticos de hoy han logrado esa claridad de perspectiva, o se han atrevido a desmenuzar la dificultad barroca de la magistral Casi nunca de Sada, como lleva a cabo Santos.

Si para ella el mexicano fue uno de los grandes renovadores de cierta tradición posmoderna, al ponerla al día, ella hace lo mismo con su crítica. Excepción hecha de Bolaño y algunos autores que no lo han percibido como modelo, aunque respeten su obra de la boca para afuera, los años 1996-2018 han sido menos un momento de contrarrevolución u oscilación del péndulo de la historia literaria contra las tendencias precedentes, y más un ajuste de cuentas internalizado por los autores antes los prescriptores mencionados arriba. Algo parecido pasó con los críticos, y ese es otro mensaje importantísimo ajustado con creces y discreción por el libro de Santos, que definitivamente es un nuevo comienzo, en gran parte por ser el menos académico de otros que se puede analizar hoy.

\section{Bibliografía}

Corral, Wilfrido H. 2015. "Latinoamericanistas españoles y narrativa contemporánea". En Condición critica. Conversaciones con Marcelo Báez Meza. Crítica revisada. Quito: Antropófago.

Santos, Elena. 2017. Epilogo provisional. Una cierta tendencia de la narrativa latinoamericana actual. Barcelona: Paso de Barca. 